\title{
Effect of unfractionated heparin, enoxaparin and sulodexide on the relations between secretion and expression of OPG, RANKL and vWF in HUVEC
}

\author{
Katarzyna Lekesiz ${ }^{1}$, Beata Naumnik ${ }^{1}$, Hanna Borysewicz-Sanczyk ${ }^{2}$, \\ Ewa Koc-Zorawska', Michal Mysliwiec ${ }^{1}$ \\ ${ }^{1}$ Department of Nephrology and Transplantation with Dialysis Unit, Medical University, \\ Bialystok, Poland \\ ${ }^{2}$ Department of Pediatrics, Endocrinology, Diabetology with Cardiology Divisions, \\ University Children's Clinical Hospital of Bialystok
}

\begin{abstract}
Heparin modulates function of vascular endothelium. We studied the effects of unfractionated heparin (UFH) vs. enoxaparin vs. sulodexide on the levels and gene expression of osteoprotegerin (OPG), Receptor Activator of Nuclear Factor $\kappa$ B Ligand (RANKL) and von Willebrand factor (vWF) in Human Umbilical Vein Endothelial Cells (HUVEC) culture. HUVEC were isolated from human umbilical vein by a standard method. The supernatant concentrations (ELISA) and gene expression (Real Time-PCR) of OPG, RANKL and vWF in HUVEC were determined after incubation with various concentrations of UFH, enoxaparin and sulodexide for up to 16 hours. In control HUVEC strong positive correlation between OPG and vWF levels was observed, whereas SRANKL negatively correlated with OPG and vWF levels. Only in control HUVEC a negative correlation between the supernatant level of vWF and its gene expression was found. Already the lowest concentration of UFH caused 2.5-fold increase in OPG gene expression while higher UFH concentrations substantially increased RANKL mRNA level. A negative correlation between the OPG and sRANKL concentration was noticed in supernatant HUVEC which were incubated with enoxaparine. In conclusion, the observed interrelationships between OPG, RANKL and vWF levels in unstimulated HUVEC support the presumption of the pathophysiological links between these proteins. Of the tested heparin formulas UFH seems to be the most potent in altering the OPG, RANKL and vWF axis. (Folia Histochemica et Cytobiologica 2013, Vol. 51, No. 2, 156-163)
\end{abstract}

Key words: heparins, sulodexide, HUVEC, osteoprotegerin, sRANKL, von Willebrand Factor, ELISA, qPCR

\section{Introduction}

Heparins are widely used in the prevention of thromboembolic disease, in patients undergoing surgical, gynecological or orthopedic procedures, in hemodialysis patients, and in many other clinical situations. Considering their all-systemic actions, effects of hepa-

Correspondence address: B. Naumnik, Department of Nephrology and Transplantation with Dialysis Unit, Medical University of Bialystok Zurawia St. 14, 15-540, Bialystok, Poland; tel./fax: +48 857434586 ; e-mail: bnaumnik@poczta.onet.pl rins on endothelial cells still remain unclear. Another drug with anticoagulant properties is sulodexide. Sulodexide presents as a heparin derivative (heparinoid), being a purified medium-molecular-weight glycosaminoglycan containing $80 \%$ of heparin sulfate and $20 \%$ of dermatan sulfate. Its anticoagulant action, like that of low-molecular-weight heparins (LMWHs), involves mainly the inhibition of the active factor X. Sulodexide has a smaller effect on thrombin (IIa), which helps to avoid hemorrhagic effects during its administration.

Osteoprotegerin (OPG) is a tumor necrosis factor (TNF) family glycoprotein [1]. OPG is part of the axis of OPG/Receptor Activator of Nuclear Factor 
$\kappa \mathrm{B}$ (RANK)/Receptor Activator of Nuclear Factor $\kappa \mathrm{B}$ Ligand (RANKL). RANKL, binding to its receptor (RANK) expressed on the surface of target cells, triggers a cascade of intercellular signals that activate transcription factors (e.g. NF $\kappa \beta$, N-terminal c-Jun kinase pathway) responsible for the maturation of osteoclasts. OPG competes with RANKL, blocking its binding to RANK, and thus inhibits osteoclastogenesis and counteracts bone mass loss [1].

The von Willebrand factor (vWF) is synthesized by endothelial cells and megakaryocytes, and then released to blood in the form of multimers. Its role in the process of hemostasis is to ensure proper platelet adhesion to injured sites in vascular endothelium and to protect factor VIII from its proteolytic degradation. The elevated level of vWF correlates with the degree of endothelial damage and constitutes a risk factor for thrombosis [2].

OPG is physiologically associated with vWF in Weibel -Palade bodies of endothelial cells [3]. Heparins are known to exert well-documented effects on the release of vWF [4] and OPG [5] in vivo. To date, however, it has been unclear whether these effects are associated with each other.

The study objective was to compare the effect of chosen heparins (UFH, unfractionated heparin, as well as LMWH, enoxaparin) and sulodexide on the concentrations and gene expression of OPG, RANKL and $\mathrm{vWF}$ in the cultures of endothelial cells of the human umbilical vein (HUVECs).

\section{Material and methods}

HUVEC culture. Endothelial cells of the human umbilical vein were used as material for the study. The umbilical cord was provided immediately after delivery of a healthy full-term newborn from normal pregnancy. The study was performed in conformity with Helsinki Declaration and local Ethics Committee approval was obtained. Cell isolation and arrangement of HUVEC culture followed standard procedures according to Jaffe $[6,7]$. The umbilical vein was cannulated and perfused with HBSS solution (without $\mathrm{Ca}^{++}$and $\mathrm{Mg}^{++}$) to remove blood and clots. Next, incubation was performed in a heated bath at $37^{\circ} \mathrm{C}$ for $10 \mathrm{~min}$. Cell suspension was centrifuged and then the sediment containing HUVEC was placed in culture bottles (surface area of $75 \mathrm{~cm}^{3}$ ) coated with fibronectin (Nagle Nunc Intl. Inc., Penfield, NY, USA). We used M199 medium (SigmaAldrich Co., St. Louis, Missouri, USA) supplemented with $20 \%$ fetal calf serum, streptomycin $100 \mu \mathrm{g} / \mathrm{mL}$, amphotericin B $0.25 \mu \mathrm{g} / \mathrm{mL}$, penicillin G $100 \mathrm{IU} / \mathrm{mL}$, ECGF $200 \mu \mathrm{g} / \mathrm{mL}$ (all purchased from SigmaAldrich). The cells were incubated in an atmosphere enriched with $5 \% \mathrm{CO}_{2}(95 \%$ air $)$. The primary culture was obtained at $90 \%$ confluence by visual assess-

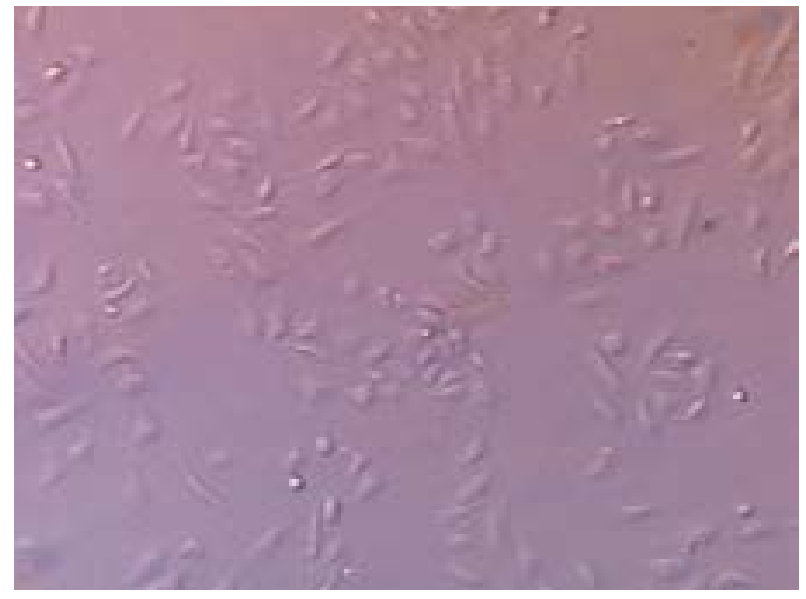

Figure 1. HUVEC (Human Umbilical Vein Endothelial Cells) colony; first day after passage. Original magnification $\times 100$

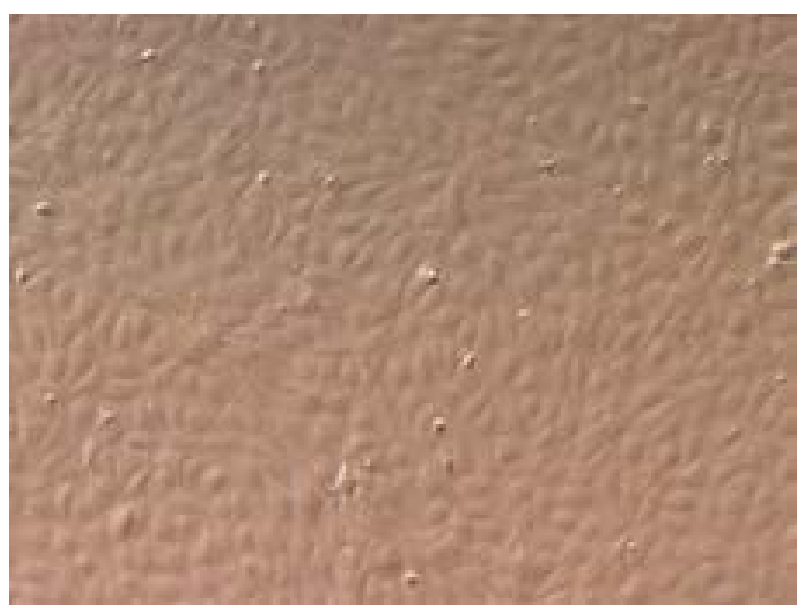

Figure 2. HUVEC colony; fifth day after passage (full confluence); $\times 100$

ment, accounting for approximately 6 million cells counted in trypsinized cell suspension in a Bürker chamber. Next, the culture was passaged according to standard procedures (Figures 1, 2), by washing the cells with serum-free M199 medium and trypsinization with $0.1 \%$ trypsin solution. The reported experiment was conducted at the third passage. For experimental purposes, the cells were sieved onto 24-pit culture plates (Nagle Nunc). In order to identify HUVECs, the culture was labeled with monoclonal antibodies against von Willebrand factor (Dako, Glostrup, Denmark). The medium used in the experiment contained neither heparin nor any other anticoagulant.

Study design. All HUVECs used for the study were obtained from the same umbilical vein. Doses and timing of drug administration were calculated according to their pharmacokinetic properties. The cells were cultured in 24 -well 
Table 1. Trade names of the TaqMan kits used

\begin{tabular}{|l|l|}
\hline Gene & $\begin{array}{l}\text { Gene Expression TaqMan } \\
\text { Assay Kit }\end{array}$ \\
\hline OPG - TNFRSF11B & Hs00900358_m1 (FAM) \\
\hline RANKL - TNFSF11 & Hs00243522_m1 (FAM) \\
\hline vWF - VWF & Hs00169795_m1 (FAM) \\
\hline 18S rRNA & Hs03928985_g1 (FAM) \\
\hline
\end{tabular}

Abbreviation: FAM - 6-carboxyfluorescein-labeled probe

culture plates (approximately $2.5 \times 10^{5}$ cells). The cultures were supplemented with unfractionated heparin at various concentrations $(4,20$ and $40 \mu \mathrm{g} / \mathrm{mL})$ for 1,2 and 6 hours, and with enoxaparin $(10,50,100 \mu \mathrm{g} / \mathrm{mL})$ for 4,8 and 16 hours. Additionally, sulodexide was applied at concentrations of $0.1,0.5$ and $1 \mu \mathrm{g} / \mathrm{mL}$ for 2, 4 and 6 hours of incubation. Unstimulated cultures were used as controls. Supernatant was obtained by pipetting it gently off HUVECs, and placing in Eppendorf tubes.

Measurement of OPG, sRANKL and vWF secretion by HUVEC (ELISA). Supernatant concentrations of OPG (RayBiotech, Norcross, GA, USA), soluble (s)RANKL (Biomedica Group, Vienna, Austria) and vWF (Abnova, Taipei City, Taiwan) were determined by immunoenzymatic assays (ELISA) following the manufacturers' instructions.

Isolation of HUVEC RNA. Buffer RLT plus $(350 \mu \mathrm{l})$ containing $\beta$-mercaptoethanol was added to HUVEC (10 $\mu \mathrm{l}$ ME per $1 \mathrm{ml}$ of buffer RLT) (SigmaAldrich). Next, the cells were 'scratched' using a pipette tip and transferred to a QIAshredder column (QIAGEN, Hilden, Germany). A QIAshredder kit was used for homogenization performed during centrifugation of the suspension for $2 \mathrm{~min}$ at the maximum speed. Subsequently, HUVEC RNA was isolated according to the producer's instructions (RNAeasy Plus Mini Kit, QIAGEN, Hilden, Germany ).

Measurement of OPG, RANKL and vWF mRNA levels in HUVEC by Real Time PCR. All the reagents used at this stage of the experiment were purchased from Applied Biosystems (Foster City, CA, USA). High capacity RNA-to -cDNA kit was applied to induce the reverse transcription process in the obtained RNA. Real Time PCR was performed to assess the expression of the genes examined, using cDNA and oligonucleotide starters specific for the OPG, RANKL, vWF and 18S RNA genes as a matrix (Table 1). For these reactions we used a TaqMan Gene Expression Assay kit. As a reference system, TaqMan Ribosomal RNA Control Reagents kit was employed to amplify 18S rRNA gene. The PCR was started with an incubation at $95^{\circ} \mathrm{C}$ for $10 \mathrm{~min}\left(30 \mathrm{cycles}\right.$ for $30 \mathrm{sec}$ at $\left.95^{\circ} \mathrm{C}\right)$, followed by incubation at $55^{\circ} \mathrm{C}$ for $30 \mathrm{sec}$ (binding temperature). Binding of the polymerase and synthesis of the complementary strand to the matrix took place at $72^{\circ} \mathrm{C}$ for $30 \mathrm{sec}$, whereas termination of the reaction lasted for $10 \mathrm{~min}$ at $4^{\circ} \mathrm{C}$.

The $2^{-\Delta C T}$ values were used to analyze the correlations of OPG, RANKL and vWF gene expression. In real time PCR, the CT (threshold cycle) values were calculated for OPG, RANKL, vWF and ribosomal RNA (reference gene; 18S rRNA) as the mean from three CT measurements. Livak's comparative method was applied to determine the relative level of gene expression (8) in relation to the reference gene (18S rRNA). The normalized value of the relative gene expression in an unknown sample in regard to the calibrator was calculated according to the formula: Fold Change $(\mathrm{R})=$ $=2^{-\Delta \Delta \mathrm{CT}}$. The results so obtained are expressed as calibration (control) sample multiple. When the $\mathrm{R}$ parameter equals 1 , the expression levels or the number of gene copies in the calibration and unknown samples are identical. For gene expression (PCR) analysis the mRNA level of studied genes was defined in control cells as 1 . The value lower than 1 indicates higher gene expression in the calibration sample, whereas higher than 1 suggests higher gene expression in the unknown sample $[8,9]$.

Statistical analysis. The results of this preliminary study represent data obtained from two sets of cell incubations. Shapiro-Wilk's W test of normality was used for data distribution analysis. The Spearman's rank correlation coefficient was determined for all variables. Differences at $\mathrm{p}<0.05$ were considered statistically significant. Statistica program v. 10.0 (StatSoft, Cracow, Poland) was used for calculations.

\section{Results}

\section{Concentrations (ELISA) and gene expression (PCR) of OPG, RANKL and $v W F$ in control HUVEC}

In control HUVECs, the levels (ELISA) of OPG and $\mathrm{VWF}$ in cell supernatant increased with the experiment's duration (Figures 3A, C) whereas the concentration of sRANKL, decreased during the course of incubation (mainly after 6 and 8 hours) (Figure 3B).

A number of correlations related mainly to protein concentrations was observed in the unstimulated cel1s. A strong positive correlation was found between the concentrations of OPG and vWF $(\mathrm{R}=0.966$, $\mathrm{p}<0.001)$ in HUVEC supernatant. Simultaneously, negative correlations between the levels of OPG and sRANKL $(\mathrm{R}=-0.750, \mathrm{p}=0.019)$ and between sRANKL and vWF, $(\mathrm{R}=-0.850, \mathrm{p}=0.003)$ were observed. Interestingly, in control HUVECs a negative correlation between the level of vWF and its gene expression was found $(\mathrm{R}=-0.783, \mathrm{p}=0.012)$. 


\section{The effect of unfractionated heparin on the concentration (ELISA) and gene expression (qPCR) of OPG, RANKL and $v W F$ in HUVEC}

The lowest concentration of UFH $(4 \mu \mathrm{g} / \mathrm{mL})$, compared with the control, caused a gradual and the most substantial increase in the supernatant OPG levels, which was also observed with less intensity for the concentration of $20 \mu \mathrm{g} / \mathrm{mL}$ (Figure 3A). The incubation of HUVEC in the presence of UFH (especially at the lowest dose) decreased sRANKL concentration (Figure 3B). With the experiment duration, a trend was observed towards a gradual increase in vWF concentration, being most distinct at the highest UFH dose (Figure 3C).

Unfractionated heparin caused a 2.5 -fold increase in OPG gene expression as compared with the control, but only at the lowest dose and shortest time of incubation (Table 2A). However, in the remaining cases, UFH caused a decline in the expression of the OPG gene. In the case of RANKL mRNA, a substantial increase (even 1433-fold) was noted for each UFH dose and incubation time. At the same time the gene expression of vWF showed a trend towards a substantial decrease (Table 2A). During incubation of HUVECs with UFH, no significant correlations were found either between the concentrations of the proteins studied or between the expression levels of their genes.

\section{The effect of enoxaparin on the concentration (ELISA) and expression (qPCR) of OPG, RANKL and $v W F$ in HUVEC}

HUVEC incubation with enoxaparin was associated with an increase in the level of OPG in supernatant as compared with the control, which was most distinctive after 16 hours of incubation at all concentrations used (Figure 4A). The highest dose of enoxaparin induced the greatest increase in the level of sRANKL after the first stage of incubation which gradually decreased in the subsequent hours of the experiment (Figure 4B). Lower doses of enoxaparin did not change sRNAKL supernatant levels as compared with control cells. The concentration of vWF after incubation of HUVECs with enoxaparin increased with time (Figure 4C). Enoxaparin at the concentration of 50 and $100 \mu \mathrm{g} / \mathrm{mL}$ increased vWF level in HUVEC supernatant after 4 and 8 hours of incubation, however, at the later stages of incubation $\mathrm{vWF}$ levels prominently decreased after incubation with enoxaparin at the dose of $100 \mu \mathrm{g} / \mathrm{mL}$ (Figure 4C). Enoxaparin caused a falling trend in OPG gene expression (Table 2B). RANKL gene expression showed a substantial increase after the lowest dose of enoxaparin and the shortest incubation period (a 301fold increase as compared with the control). In the other cases, RANKL expression was found to rise only
$\mathbf{A}$

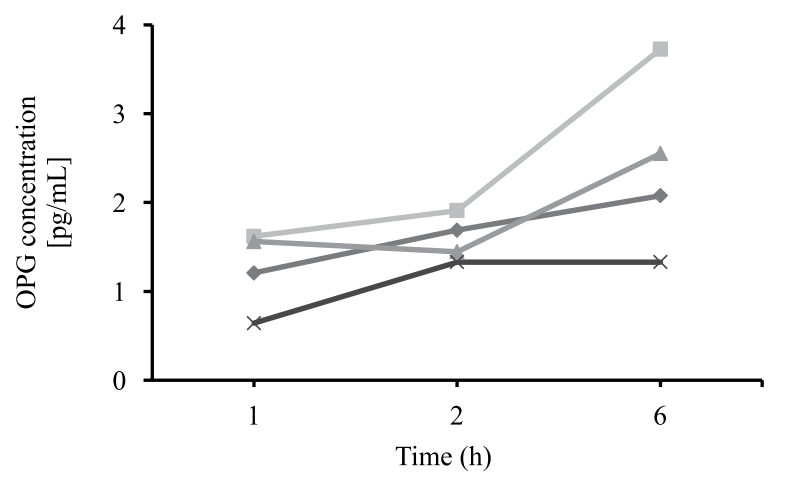

B

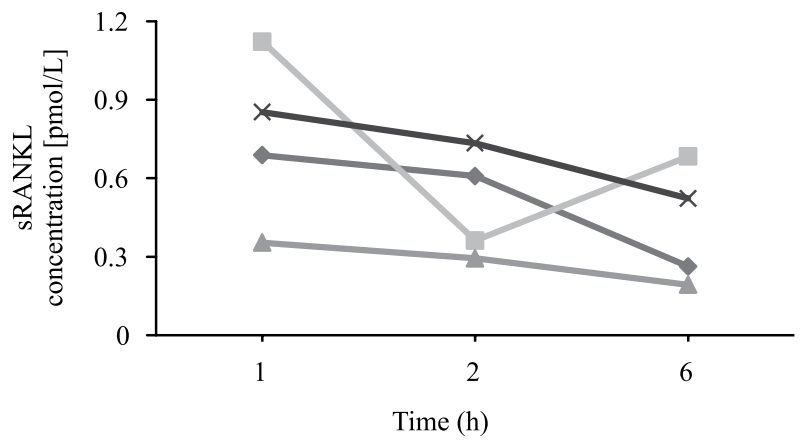

C

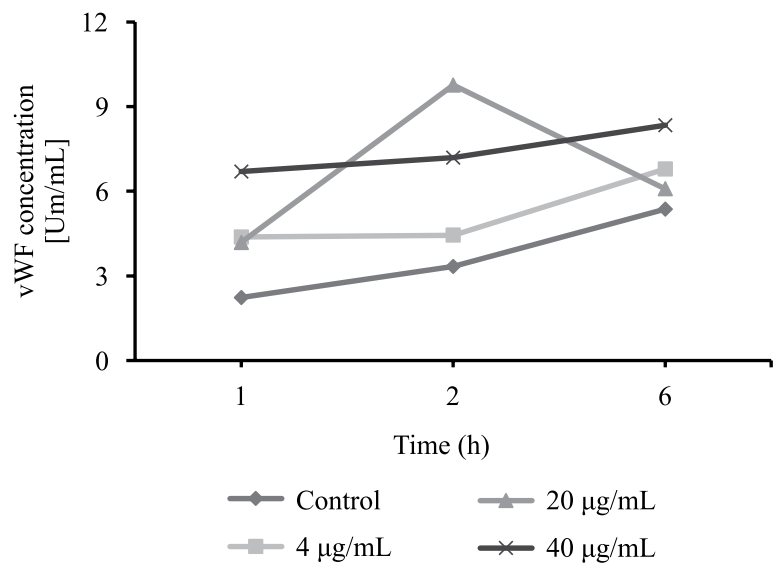

Figure 3. Concentration of OPG (A), sRANKL (B) and vWF (C) in the supernatants of control HUVECs and in cells incubated with various concentrations of unfractionated heparin (UFH). Control - HUVECs incubated without heparins, OPG - Osteoprotegerin, sRANKL soluble Receptor Activator of Nuclear Factor kB Ligand, vWF - von Willebrand Factor, h - hour

slightly or even decrease (Table 2). The expression of the $\mathrm{vWF}$ gene increased at small drug concentration and decreased at the higher ones (Table 2B).

Under the enoxaparin usage we observed a negative correlation between the concentration of OPG and sRANKL in HUVEC culture supernatant $(\mathrm{R}=-0.733, \mathrm{p}=0.024)$. 
A

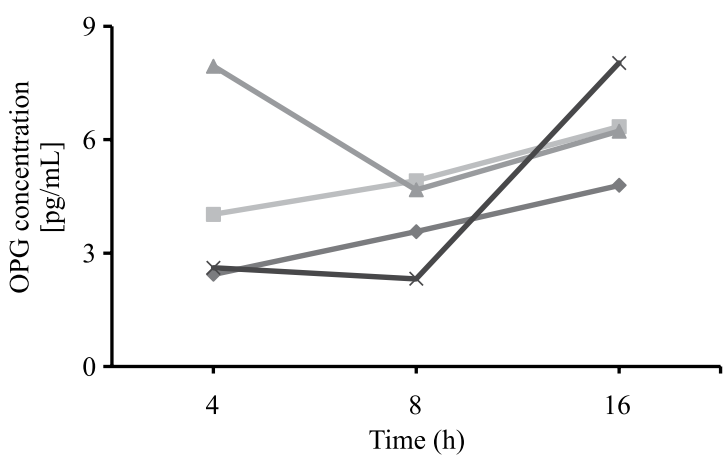

B

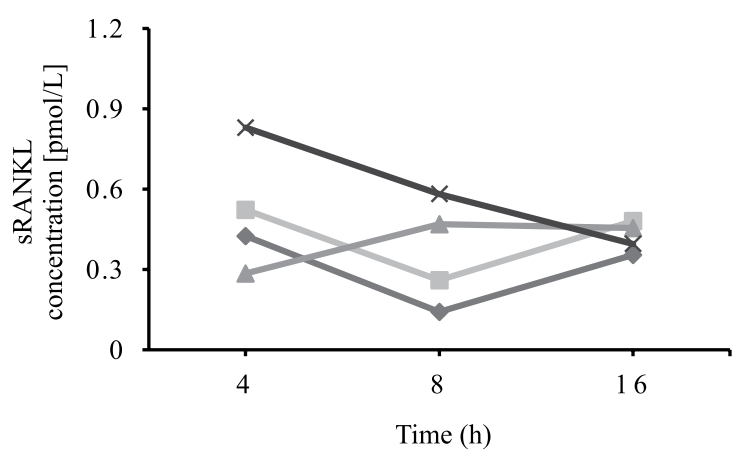

C

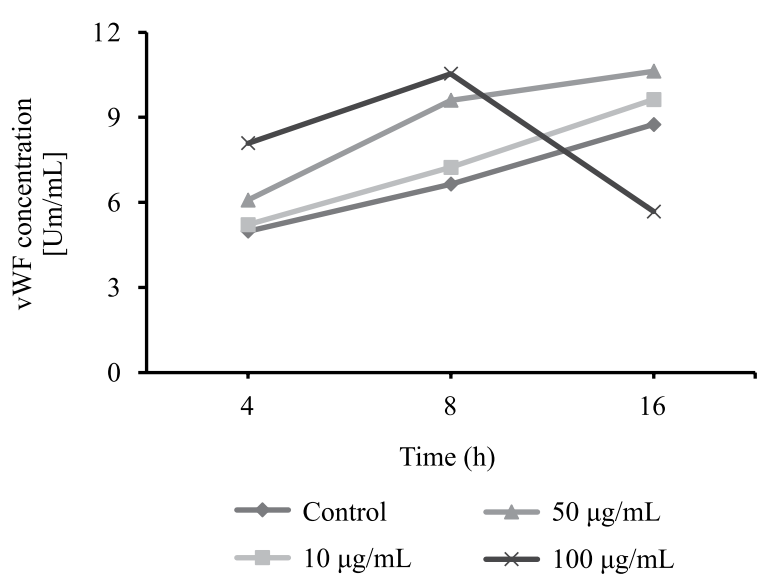

Figure 4. Concentration of OPG (A), sRANKL (B) and vWF (C) in the supernatants of control HUVECs and in cells incubated with various concentrations of enoxaparin. Control - HUVECs incubated without heparins, OPG - Osteoprotegerin, sRANKL - soluble Receptor Activator of Nuclear Factor kB Ligand, vWF — von Willebrand Factor, h - hour

\section{The effect of sulodexide on the concentration (ELISA) and gene expression (qPCR) of OPG, RANKL and $v W F$ in HUVEC}

Under sulodexide supplementation we did not observe any relevant changes in the OPG, sRANKL and $\mathrm{vWF}$ concentrations in HUVEC supernatant compared with the control (Figure 5). Sulodexide caused a decrease in the OPG gene expression, although a slight increase was noted when HUVECs were incubated for 4 hours at its $0.5 \mu \mathrm{g} / \mathrm{mL}$ concentration (Table 2C). The expression of the gene encoding RANKL remained lower than control levels during incubation of the cells with sulodexide. Only the $0.5 \mu \mathrm{g} / \mathrm{mL}$ concentration caused a 14 -fold increase in RANKL gene expression after incubation for 2 hours (Table 2C). Sulodexide, like the other drugs, reduced vWF gene expression in HUVECs, although slight increase was once noted at a low dose of the drug. During incubations of HUVECs with sulodexide, no statistically significant correlations were noted either between the proteins concentrations or between their genes' expressions.

\section{Discussion}

The current study presents the effects of different heparins and sulodexide on the relations between the OPG/RANKL system and vWF in vitro. Control HUVEC cultures showed an increase in the concentration of osteoprotegerin with incubation time. Simultaneously, strong negative correlation were noted between OPG and SRANKL as well as positive one between OPG and vWF levels in HUVEC supernatants.

Numerous animal studies provided evidence for the protective role of OPG towards the arterial walls. OPG knockout mice showed calcification of the middle layer of the aorta and renal vessels, but not of smaller vessels [10]. However, data on a direct relationship between the level of OPG and stage of atherosclerosis in humans remain in opposition to those describing animal models. Prognostic significance of the elevated concentration of serum OPG as the risk factor of fatal cardiovascular events was described in disorders associated with atherosclerosis, e.g. in elderly women [11], hemodialysis patients [12], or diabetic patients [13]. During these states increased release of OPG can be caused by endothelial damage, internal membrane smooth muscle cell proliferation as well as advanced calcification of atheroma. If we assume a protective role of this protein, its increase in the blood in cardiovascular diseases may indicate failure of the compensatory mechanisms.

It has been suggested that the differences between UFH and LMWH in their effect on the OPG/ /RANKL system may play a role in the development of atherosclerosis. A study conducted in vivo by Vik et al. [14] presented the effect of UFH and LMWH (dalteparin) on plasma OPG concentration. Subcutaneous administration of high doses of dalteparin and 
Table 2. Values of fold change of the mRNA levels of OPG, RANKL and vWF genes during the incubation of HUVECs with unfractionated heparin (UFH), enoxaparin and sulodexide

\begin{tabular}{|c|c|c|c|c|c|c|c|c|c|}
\hline $\mathbf{A}$ & & \multicolumn{3}{|c|}{ UFH $\left(2^{-\Delta \Delta C T}\right)$} & \multirow{2}{*}{$\begin{array}{l}\text { B } \\
\text { Con. }\end{array}$} & \multirow[b]{2}{*}{ Time } & \multicolumn{3}{|c|}{ Enoxaparin $\left(2^{-\Delta \Delta C T}\right)$} \\
\hline Con. & Time & OPG & RANKL & vWF & & & OPG & RANKL & $\mathrm{vWF}$ \\
\hline $4 \mu \mathrm{g} / \mathrm{mL}$ & $1 \mathrm{~h}$ & 2.45 & 1433.57 & 0.0058 & $10 \mu \mathrm{g} / \mathrm{mL}$ & $4 \mathrm{~h}$ & 0.31 & 301.92 & 0.00067 \\
\hline $4 \mu \mathrm{g} / \mathrm{mL}$ & $2 \mathrm{~h}$ & 0.76 & 611.29 & 0.002 & $10 \mu \mathrm{g} / \mathrm{mL}$ & $8 \mathrm{~h}$ & 0.36 & 0.51 & 13.607 \\
\hline $4 \mu \mathrm{g} / \mathrm{mL}$ & $6 \mathrm{~h}$ & 0.30 & 192.16 & 0.025 & $10 \mu \mathrm{g} / \mathrm{mL}$ & $16 \mathrm{~h}$ & 1.77 & 1.59 & 24.75 \\
\hline $20 \mu \mathrm{g} / \mathrm{mL}$ & $1 \mathrm{~h}$ & 0.57 & 354.7 & 0.0019 & $50 \mu \mathrm{g} / \mathrm{mL}$ & $4 \mathrm{~h}$ & 0.99 & 2.47 & 0.40 \\
\hline $20 \mu \mathrm{g} / \mathrm{mL}$ & $2 \mathrm{~h}$ & 0.87 & 1070.96 & 0.0056 & $50 \mu \mathrm{g} / \mathrm{mL}$ & $8 \mathrm{~h}$ & 2.38 & 4.31 & 13.50 \\
\hline $20 \mu \mathrm{g} / \mathrm{mL}$ & $6 \mathrm{~h}$ & 0.40 & 135.23 & 0.046 & $50 \mu \mathrm{g} / \mathrm{mL}$ & $16 \mathrm{~h}$ & 0.28 & 0.427 & 0.649 \\
\hline $40 \mu \mathrm{g} / \mathrm{mL}$ & $1 \mathrm{~h}$ & 0.82 & 344.94 & 0.0022 & $100 \mu \mathrm{g} / \mathrm{mL}$ & $4 \mathrm{~h}$ & 0.48 & 3.20 & 0.027 \\
\hline $40 \mu \mathrm{g} / \mathrm{mL}$ & $2 \mathrm{~h}$ & 0.10 & 12.47 & 4.24E-05 & $100 \mu \mathrm{g} / \mathrm{mL}$ & $8 \mathrm{~h}$ & 0.38 & 1.31 & 0.49 \\
\hline $40 \mu \mathrm{g} / \mathrm{mL}$ & $6 \mathrm{~h}$ & 0.26 & 372.82 & 0.0026 & $100 \mu \mathrm{g} / \mathrm{mL}$ & $16 \mathrm{~h}$ & 1.28 & 0.84 & 0.70 \\
\hline C & & \multicolumn{3}{|c|}{ Sulodexide $\left(2^{-\Delta \Delta C T}\right)$} & \multicolumn{5}{|c|}{ Control definite as 1} \\
\hline Con. & Time & OPG & RANKL & vWF & & & & & \\
\hline $0.1 \mu \mathrm{g} / \mathrm{mL}$ & $2 \mathrm{~h}$ & 0.18 & 0.736 & 0.72 & & & & & \\
\hline $0.1 \mu \mathrm{g} / \mathrm{mL}$ & $4 \mathrm{~h}$ & 1.13 & 2.74 & 0.34 & & & & & \\
\hline $0.1 \mu \mathrm{g} / \mathrm{mL}$ & $6 \mathrm{~h}$ & 0.189 & 0.95 & 1.49 & & & & & \\
\hline $0.5 \mu \mathrm{g} / \mathrm{mL}$ & $2 \mathrm{~h}$ & 1.71 & 14.02 & 0.55 & & & & & \\
\hline $0.5 \mu \mathrm{g} / \mathrm{mL}$ & $4 \mathrm{~h}$ & 0.70 & 0.88 & 0.156 & & & & & \\
\hline $0.5 \mu \mathrm{g} / \mathrm{mL}$ & $6 \mathrm{~h}$ & 0.158 & 0.47 & 0.086 & & & & & \\
\hline $1 \mu \mathrm{g} / \mathrm{mL}$ & $2 \mathrm{~h}$ & 0.76 & 0.472 & 0.008 & & & & & \\
\hline $1 \mu \mathrm{g} / \mathrm{mL}$ & $4 \mathrm{~h}$ & 0.685 & 0.608 & 0.035 & & & & & \\
\hline $1 \mu \mathrm{g} / \mathrm{mL}$ & $6 \mathrm{~h}$ & 0.355 & 0.48 & 0.039 & & & & & \\
\hline
\end{tabular}

Abbreviation: Fold Change $=2^{-\Delta \Delta C T} ; \Delta \Delta \mathrm{CT}=\Delta \mathrm{CT}$ (unknown sample) $-\Delta \mathrm{CT}$ (calibrator); Control $-\mathrm{HUVEC}$ without drugs; Con. - Concentration; OPG, sRANKL, vWF as described for Figure 3

intravenous application of low doses of UFH were found to increase plasma OPG level in a similar way. However, UFH showed higher affinity to OPG than dalteparin [14]. Most recent observations referred to the intravenous use of both heparins [15], revealed no statistically significant differences between UFH or LMWH (fraxiparine) in increased OPG release. However, the use of fraxiparine was associated with lower increase of OPG plasma level during the first 15 minutes of hemodialysis procedure [15]. We are not aware of any reports regarding the effect of heparins on OPG release in vitro.

In our study, the control HUVECs may be regarded as an example of the physiological release of the studied proteins in response to mechanical cell damage associated with cell culture technique. We demonstrated a strongly positive correlation between the concentrations of OPG and vWF in HUVEC control. The vWF is physiologically related to OPG by its A1 domain. The vWF-OPG complexes originate only 
A

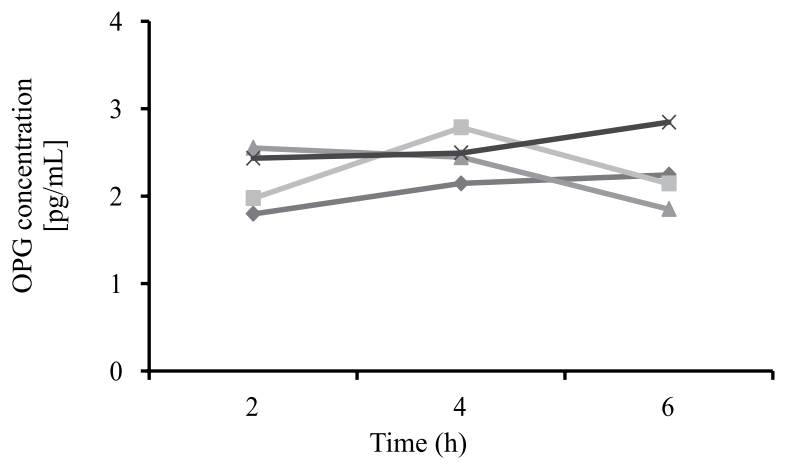

B

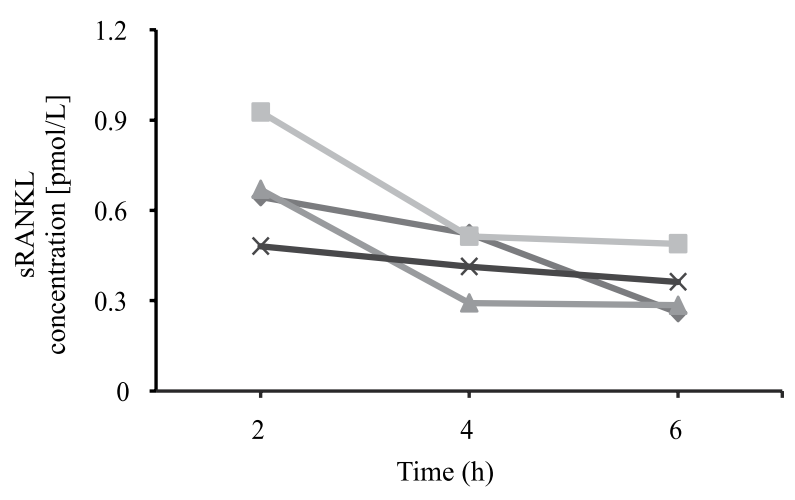

C

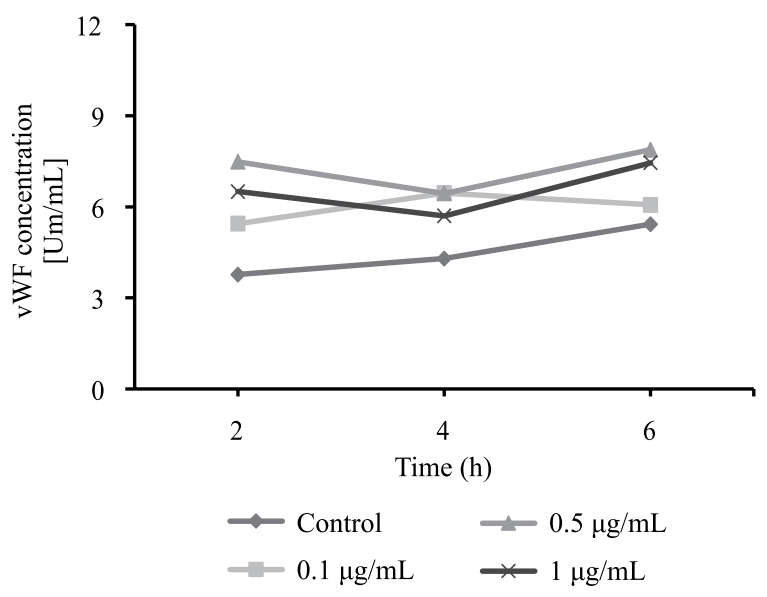

Figure 5. Concentration of OPG (A), sRANKL (B) and vWF (C) in the supernatants of control HUVECs and in cells incubated with various concentrations of sulodexide. Control - HUVECs incubated without heparins, OPG Osteoprotegerin, sRANKL - soluble Receptor Activator of Nuclear Factor kB Ligand, vWF — von Willebrand Factor, h - hour

via intracellular formation, and the reaction requires high level of calcium ions, low level of chlorine ions and $\mathrm{pH}$ 6.5. OPG and $\mathrm{vWF}$ are probably formed in the Golgi apparatus and stored as complexes in Weibel-Palade bodies [16]. The observed simultaneous release of OPG and vWF by control cells (positive correlation) confirms this physiological relationship. Heparins, by activating the endothelium, release OPG and $\mathrm{vWF}$ from storage vesicles in HUVECs culture.

In control HUVEC we also found negative correlations between sRANKL and OPG concentration, as well as between sRANKL and vWF levels, which confirms the physiological axis of these proteins. One of the hypotheses suggests the relationship between changes in the levels of OPG and RANKL in the course of cardiovascular diseases. The association involves an incomplete compensatory mechanism, which at once presents a question referring to the involvement of RANKL and its receptors in the calcification of atheromas. It has been assumed that the 'proinflammatory' profile of cytokines observed in atherosclerosis increases the RANKL/OPG ratio and in this way causes accumulation of calcium deposits [17]. Our in vitro findings seem to confirm numerous reports on the presence of inverse relationship between the concentration of OPG and RANKL also in vessels that are free of calcification [18].

In our study, control endothelial cells showed a strong negative correlation between the concentration of $\mathrm{vWF}$ and sRANKL. It is likely that the relationship between vWF and sRANKL is similar to that observed in the case of OPG and sRANKL.

We also observed a negative correlation between the expression of the vWF gene in cells and its concentration in control HUVEC supernatant. The cells showed a rapid release of vWF and its gradually increasing expression reaching the peak during the final stage of the experiment. This is consistent with previous reports on a spontaneous release of $\mathrm{vWF}$ by HUVEC from Weibel-Palade bodies via exocytosis [19]. Galbusera et al. demonstrated an association between the increase in vWF concentration in HUVEC supernatant and shear stress of blood flow [19]. However, also in the control, the level of vWF was found to increase with incubation time. No difference was observed in the expression of the gene encoding $\mathrm{vWF}$ between control and drugs stimulated culture [19]. We observed a negative correlation between the expression of vWF and its concentration in the supernatant, but only in the control HUVECs. Incubation with UFH decreased vWF expression, which could be related to partial HUVEC exhaustion under strong UFH stimulation.

In our study, enoxaparin in the lowest concentration, impaired the release and expression of OPG, RANKL and $\mathrm{vWF}$ as compared with control cells and other tested drugs. It was the only drug which did not changed a negative correlation between the concentration of OPG and SRANKL, observed in control cells. This observation remains consistent with reports on the protective effect of low molecular 
weight heparin on vascular endothelium, and on less pronounced extra-anticoagulation effects in patients treated with the LMWH $[20,21]$.

We found no correlations between the gene expression in HUVEC and proteins concentration in the supernatant when the cells were incubated with UFH. Thus, it seems that UFH had the strongest effects on the OPG, sRANKL and vWF axis. Heparins reduced sRANKL concentration in the supernatant. The level of RANKL expression remains low in healthy vessels, yet, it is much higher at the site of rupture of coronary blood clot [22]. However, our in vitro experiments show that the expression of the RANKL gene was markedly elevated during incubation of HUVECs with unfractionated heparin, and much less increased when enoxaparin was used. Thus, it is likely that prolonged incubation with UFH may increase the level of sRANKL in cell supernatant due to the increased expression of RANKL gene.

In conclusion, the observed relationships between OPG, RANKL and vWF levels and gene expression, affirmed mainly in control, unstimulated HUVECs, reinforces the presumption of the pathophysiological linkage between these proteins. UFH occurred to be the most potent heparin which disturbs OPG/ /RANKL/vWF axis. Our findings help to understand, but surely do not fully explain, the influence of anticoagulant drugs on the endothelial cells in vitro.

\section{Acknowledgments}

This work was supported by grant No N N402 419638 from the National Research Committee, Poland. The authors were not financially supported by any drug's manufacturer. We are indebted to Dr. Oksana Kovalchuk for laboratory assistance.

\section{References}

1. Bound'huin M, Lamoureux F, Duplomb L, Rèdini F, Heymann D. RANKL, RANK, osteoprotegerin: key partners of osteoimmunology and vascular diseases. Cell Mol Life Sci 2007;64:2334-2350.

2. Becker CR. The investigation of biomarkers in cardiovascular diseases: time for a coordinated, international effort. Eur Heart J. 2005;26:421-422.

3. Zannettino AC, Holding CA, Diamond P et al. Osteoprotegerin (OPG) is localized to the Weibel-Palade bodies of human vascular endothelial cells and is physically associated with von Willebrand factor. J Cell Physiol. 2005;204:714-723.

4. Montalescot G, Philippe F, Ankri A et al. Early increase of von Willebrand factor predicts adverse outcome in unstable coronary artery disease: beneficial effects of enoxaparin. Circulation. 1998;98:294-299.
5. Vik A, Brodin E, Sveinbjørnsson B, Hansen JB. Heparin induces mobilization of osteoprotegerin into the circulation. Thromb Haemost. 2007;98:148-154.

6. Jaffe EA, Nachman RL, Becker CG, Minick CR. Culture of human endothelial cells derived from umbilical veins. Identification by morphologic and immunologic criteria. J Clin Invest. 1973;52:2745-2756.

7. Nachman RL, Jaffe EA. Endothelial cells culture: beginnings of modern vascular biology.J Clin Invest. 2004;114:1037-1040.

8. Livak KJ, Schmittgen TD. Analysis of relative gene expression data using real-time quantitative PCR and the 2(-Delta Delta C(T)) Method. Methods. 2001;25:402-408.

9. Schmittgen TD, Livak KJ. Analyzing real-time PCR data by the comparative C(T) method. Nat Protoc 2008;3:1101-1108.

10. Bucay N, Sarosi I, Dunstan CR et al. Osteoprotegerin mice develop early onset osteoporosis and arterial calcification. Genes Dev. 1998;12:1260-1268.

11. Browner WS, Lui LY, Cummings SR. Associations of serum osteoprotegerin levels with diabetes, stroke, bone density, fractures, and mortality in elderly women. J Clin Endocrinol Metab. 2001;86:631-637.

12. Morena M, Terrier N, Jaussent I et al. Plasma osteoprotegerin is associated with mortality in hemodialysis patients. J Am Soc Nephrol. 2006;17:262-270.

13. Rasmussen LM, Tarnow L, Hansen TK, Parving HH, Flyvbjerg A. Plasma osteoprotegerin levels are associated with glycaemic status, systolic blood pressure, kidney function and cardiovascular morbidity in type 1 diabetic patients. Eur J Endocrinol. 2006;154:75-81.

14. Vik A, Brodin E, Sveinbjørnsson B, Hansen JB. Heparin induces mobilization of osteoprotegerin into the circulation. Thromb Haemost. 2007;98:148-154.

15. Cianciolo G, La Manna G, Donati G et al. Effects of unfractioned heparin and low-molecular-weight heparin on osteoprotegerin and RANKL plasma levels in haemodialysis patients. Nephrol Dial Transplant 2011;26:646-652.

16. Shahbazi S, Lenting PJ, Fribourg C et al. Characterization of the interaction between von Willebrand factor and osteoprotegerin. J Thromb Haemost. 2007;5:1956-1962.

17. Collin-Osdoby P. Regulation of vascular calcification by osteoclast regulatory factors RANKL and osteoprotegerin. Circ Res. 2004;95:1046-1057.

18. Avbersek-Luznik I, Balon BP, Rus I, Marc J. Increased bone resorption in HD patients: is it caused by elevated RANKL synthesis? Nephrol Dial Transplant. 2005;20:566-570.

19. Galbusera M, Zoja C, Donadelli R et al. Fluid shear stress modulates von Willebrand factor release from human vascular endothelium. Blood. 1997;90:1558-1564.

20. Pérez - Ruiz A, Montes R, Carrasco P, Rocha E. Effect of low molecular weight heparin, bamiparin, and unfractionated heparin on hemostatic properties of endothelium. Clin Appl Thrombosis/Hemostasis. 2002;8:65-71.

21. Vignoli A, Marchetti M, Balducci D, Falanga A. Differential effect of low molecular weight heparin, dalteparin and unfractionated heparin on microvascular endothelial cell hemostatic properties. Haematologica 2006;91:207-214.

22. Dhore CR, Cleutjens JP, Lutgens E et al. Differential expression of bone matrix regulatory proteins in human atherosclerotic plaques. Arterioscler Thromb Vasc Biol 2001;21:1998-2003.

Submitted: 17 May, 2013

Accepted after reviews: 19 June, 2013 